\title{
Effect of Moderate Exercise on Serum Interferon-Gamma and Interleukin-17 Levels in the Morphine Withdrawal Period
}

\author{
Ali Heidarianpour, ${ }^{1,}$ Majid Vahidian Rezazadeh, ${ }^{1}$ and Alireza Zamani ${ }^{2}$ \\ ${ }^{1}$ Department of Exercise Physiology, Bu-Ali Sina University, Hamadan, IR Iran \\ ${ }^{2}$ Professor of Immunology, Department of Immunology, School of Medicine, Hamedan University of Medical Sciences, Hamedan, IR Iran \\ "Corresponding author: Ali Heidarianpour, Department of Exercise Physiology, Bu-Ali Sina University, Hamadan, IR Iran, E-mail: heidarian317@gmail.com
}

Received 2015 January 12; Revised 2015 April 28; Accepted 2015 April 29.

\begin{abstract}
Background: Drug addiction triggers the infliction of a variety of diseases. Various subjects have indicated that during the withdrawal syndrome period, the immune system is weakened.

Objectives: This study aimed to investigate the changes in serum levels of interferon-gamma(IFN- $\gamma$ ) and interleukin-17(IL-17) during the morphine withdrawal syndrome induced by 8 weeks of moderate exercise and their effects on the immune system function.

Materials and Methods: Twenty-four male Wistar rats $(220 \pm 10 \mathrm{~g})$ were divided into four groups $(\mathrm{n}=6)$ : healthy control $(\mathrm{HC})$, addicted control (AC), healthy trained (HT), and addicted trained (AT) groups. AC and AT groups were made addicted to morphine sulfate $(0.4 \mathrm{mg} / \mathrm{mL})$ in 21 days. To ensure their dependence on morphine, naloxone $(3 \mathrm{mg} / \mathrm{kg}$, i.p.) was injected into the body of a number of the rats. HT and AT groups were made to run on a treadmill 5 days per week for 8 weeks while time and speed gradually increased. Both prior to the exercises and 24 hours after the last training session, blood samples were collected from all the animals, and serum IFN- $\gamma$ and IL-17 serum levels were measured using the ELISA method. This research was performed at the Bu-Ali Sina University, Hamadan, Iran.

Results: After 8 weeks of exercise, a significant increase was observed in the serum IFN- $\gamma$ level in the HT group (251.17 \pm 13.045$)$ in comparison with the HC group $(234 \pm 12.884)(\mathrm{P}=0.045)$. Furthermore, the serum IFN- $\gamma$ level in the AT group $(218.33 \pm 5.164)$ in comparison to the AC group $(190.67 \pm 8.477)$ showed a significant increase $(\mathrm{P}=0.000)$. In addition, the serum level of IFN- $\gamma$ in the HT group showed a significant increase compared to the AT group $(\mathrm{P}=0.000)$. After 8 weeks of exercise, there was a significant decrease in the serum IL-17 level in the HT group (22.67 \pm 4.46$)$ compared with the HC group (38.17 \pm 7.68$)(P=0.005)$. In addition, a significant decrease was observed in serum IL-17 in the AT group $(42.17 \pm 7.41)$ in comparison with the AC group $(57.17 \pm 7.83)(\mathrm{P}=$ 0.007). In addition, the serum IL-17 level in the HT group significantly decreased in comparison with the AT group $(\mathrm{P}=0.001)$.

Conclusions: Moderate exercise for 8 weeks increased the IFN- $\gamma$ and decreased the IL-17 serum levels in the morphine-dependent rats. For this reason, this type of exercise can improve the function of the immune system during morphine withdrawal syndrome.
\end{abstract}

Keywords: Substance Withdrawal Syndrome, Morphine Dependence, Immune System, Interferon-gamma, Interleukin-17

\section{Background}

Drug addiction is one of the most common problems of the modern world and related to the development of many physical diseases, including nervous, digestive, and respiratory ailments. Morphine is an opioid drug of which chronic use causes dependence and addiction over time. After a period of dependence, as a result of withdrawal effects, the body and central nervous system react to the lack of the substance through a set of symptoms that collectively are identified as withdrawal syndrome. Some of these symptoms include chills, myalgia, restlessness, rhinorrhea, perspiration, irritability, anxiety, joint pain, insomnia, nausea, vomiting, and diarrhea (1). The existence of at least three of these signs confirms presence of withdrawal syndrome. The results of various studies suggest that during the period of drug abuse and addiction with- drawal syndrome, the immune system is weakened and its function is impaired (2).

Cytokines are one of the immune factors affected by withdrawal syndrome. As one of the most important products of the immune response, cytokines are small protein particles that are biologically very active and regulate the growth, function, and differentiation of cells, contributing to the guidance of immune responses and inflammation (3). Cytokines are secreted by many immune cells, including lymphocytes, granulocytes, macrophages and other non-immune cells (4). In addition, different types of adipose tissues, brain and contracting muscle masses can produce cytokines (5). Interferons are an important cytokine component. Interferon-gamma (IFN- $\gamma$ ) is a major pro-inflammatory cytokine, belonging to the interferon family. This cytokine is an activator of macrophages with anti-bacterial and anti-viral functions (6), of which the 
anti-inflammatory action has been proven in various studies. In addition to TCD4+cells, IFN- $\gamma$ is also produced by NK, Th1, and TCD $8^{+}$cells (7). IFN- $\gamma$ and other cytokines secreted from Th1 are involved in the elimination of intracellular pathogens (2). In addition, interleukins are a group of cytokines that are various types of proteins functioning outside the immune system. A subset of TCD4 ${ }^{+}$cells are Th17 cells and innate immune cells such as lymphocytes $\mathrm{T} \gamma \delta$, that are the main producers of interleukin-17 (IL-17) (8). IL17 is known as a pro-inflammatory cytokine that triggers the production of other pro-inflammatory factors (9). This cytokine affects endothelial cells, causing the migration of neutrophils into inflamed tissues (10).

In recent years, several studies have focused on the impact of physical activities and exercises on human health. Many of these studies have revealed the beneficial effects of sport and physical activities on physiological dysfunctions, fitness and quality of life in general (11). The quality of the physical exercises depends on the intensity, duration, and type of activity, which have different effects on the immune system. For instance, a large number of

studies have revealed that an intensive workout causes different negative outcomes such as susceptibility to upper respiratory tract infections (12), the acute reduction of immunoglobulin (13), and decreased IFN- $\gamma$ in peripheral blood (14). On the other hand, many other studies have indicated that moderate regular exercise can reduce the number of illness days (15), regulate the functions of Th1 and Th2 cells in viral clearance (16), increase the level of IFN- $\gamma$ (17), reduce the level of IL-17 (18), and show antiinflammatory effects (19).

According to the results of many studies by different researchers, decreased production of IL-17 plasma has a beneficial anti-inflammatory effect (20). Furthermore, IFN- $\gamma$ suppresses Th17 cell differentiation (21). It has already been proven that moderate exercise effects the secretion of IFN$\gamma$ and IL-17. However, the researchers of the present study pose the question of "whether moderate exercise can have beneficial effects on immune function during morphine withdrawal."

\section{Objectives}

This study aimed to investigate the changes in the serum IFN- $\gamma$ and IL-17 levels during morphine withdrawal syndrome and evaluating these effects induced by 8 weeks of moderate exercise on immune system function.

\section{Materials and Methods}

This experimental study was carried out on 24 male Wistar rats ( 8 weeks of age and weighing $220 \pm 10 \mathrm{~g}$ ). The rats were purchased from Razi Institute, Tehran, Iran. Food and water were available ad libitum. The rats were housed in transparent polycarbonate cages (3 rats in each cage). The animals were kept under a cycle of 12 hours light and 12 hours dark, a controlled temperature $\left(22-25^{\circ} \mathrm{C}\right)$, and $50 \%$ - 70\% relative humidity. All instructions were strictly considered in accordance with the ethical protocols of the national research council's 1996 guide for the care and use of laboratory animals (22). The animals were then classified into four groups of six as follows: healthy control (HC), addicted control (AC), healthy trained (HT), and addicted trained (AT) groups.

In this study, the oral method was employed to make the samples morphine dependent using morphine sulfate powder purchased from Temad company (Tehran, Iran). The rats were made addicted to morphine at concentrations of $0.1,0.2$, and $0.3 \mathrm{mg} / \mathrm{mL}$ per dose for 48 hours (a total of 6 days) mixed into the animals' drinking water. Then, the animals were fed morphine at a concentration of 0.4 $\mathrm{mg} / \mathrm{mL}$ for 15 days. To remove the bitter taste of the morphine, sucrose at a concentration of $3 \%$ was added to their drinking water. To prevent the decomposition of the morphine by light, the bottles containing the morphine and water mixture were covered with a thin aluminum foil. To ensure the dependence of the rats on morphine, on day 21 , naloxone at a concentration of $3 \mathrm{mg} / \mathrm{kg}$ was intraperitoneally injected into some of the rats' bodies at random. Withdrawal symptoms in the animals were assessed after the injection. A mirror chamber was used for this purpose, and the animals that received naloxone for $30 \mathrm{~min}$ utes were placed inside the chamber to evaluate their behavior qualitatively.

The rats ran on a treadmill designed for animals (made by Arian Instruments, Iran) based on a program adapted from Calegari et al. (23). HC and AC groups were only allowed to move in their cages, while the HT and AT groups began running on the treadmill. The rats exercised once per day, 5 days per week, for a total of 8 weeks. During the first week, they ran for 10 minutes at a speed of $9 \mathrm{~m} /$ minutes, but the time and speed were gradually increased so that in the final week, they could reach 60 minutes at a speed of $30 \mathrm{~m} /$ minutes. The speed and duration of the exercise per week are presented in Table 1.

After the confirmation of morphine dependence of all four groups of animals in this research, blood samples were taken and deposited in serum separator tubes at room temperature for 30 minutes. Then, the blood samples were centrifuged for 10 minutes at $6^{\circ} \mathrm{C}$ at $3000 \mathrm{RPM}$. The obtained serum was immediately frozen at $-20^{\circ} \mathrm{C}$. The blood sampling process was undertaken at the end of the 8 weeks of the exercise protocol, and again 24 hours after the last exercise. enzyme linked immune sorbent as- 
Table 1. Schematic Representation of Moderate Exercise Protocol

\begin{tabular}{lccccccc}
\hline Weeks & $\mathbf{1}$ & $\mathbf{2}$ & $\mathbf{3}$ & $\mathbf{4}$ & $\mathbf{5}$ & $\mathbf{6}$ & $\mathbf{7}$ \\
\hline Time, min & 10 & 15 & 20 & 25 & 30 & 40 \\
Speed, $\mathbf{m} / \mathbf{m i n}$ & 9 & 12 & 15 & 18 & 21 & 24 & 27 \\
\hline
\end{tabular}

say (ELISA) kits were used to measure IFN- $\gamma$ (Quantikine, $\mathrm{R}$ and D Systems, USA) and IL-17 (Cusabio Biotech Co. Ltd., Wuhan, China) cytokines. To do so, a fully automatic Elisa reader, Elisys UNO, manufactured by “Human" in Germany was employed.

The statistical software SPSS, version 16 was used to analyze the data. The normality of the data was tested and confirmed by the Shapiro-Wilk test. The data were analyzed statistically via one-way analysis of variance (ANOVA), and the means were compared using Tukey's test. The data were expressed as mean \pm SD and the differences were considered significant at $\mathrm{P}<0.05$. This research was carried out at BuAli Sina University, Hamadan, Iran.

\section{Results}

The findings showed that compared to the HC group, the serum IFN- $\gamma$ level significantly decreased in the AC group after 21 days of addiction and prior to the 8-week moderate exercise protocol $(\mathrm{P}<0.001)$. Moreover, a significant decrease was observed in the level of serum IFN- $\gamma$ in the AT group compared with the HT group $(\mathrm{P}<0.001)$.

On the other hand, there was no significant difference in the serum IFN- $\gamma$ levels between the HC and HT groups (P $>0.05)$. No significant difference was found between the serum IFN- $\gamma$ levels in the AC and AT groups ( $\mathrm{P}>0.05)$. The results are illustrated in Table 2 and Figure 1.

Furthermore, the results of this study showed that compared to the HC group, the serum IL-17 level significantly increased in the AC group prior to the beginning of the 8-week moderate exercise protocol $(\mathrm{P}<0.001)$.

In addition, there was a significant increase in the serum IL-17 level in the AT group compared with the HT group $(\mathrm{P}<0.001)$. On the other hand, there was no significant difference between the HC and HT groups. Likewise, there was not a significant difference between the AC and AT groups $(P>0.05)$. The obtained results are shown in Table 3 and Figure 1.

After 8 weeks of moderate exercise, there was a significant increase in the serum IFN- $\gamma$ level of the HC group compared with the AC group $(\mathrm{P}<0.001)$. Further, a significant increase in serum IFN- $\gamma$ level in the HT group was observed compared with the AT group $(\mathrm{P}<0.001)$. A significant increase was also observed in the serum IFN- $\gamma$ level in the
Table 2. Serum IFN- $\gamma$ Levels "Before" and "After" the Exercise Protocol in the Groups $(\mathrm{pg} / \mathrm{mL})^{\mathrm{a}}$

\begin{tabular}{lccc}
\hline & $\begin{array}{c}\text { Mean }^{\mathbf{b}} \\
\text { Before the exercise protocol }\end{array}$ & Min & Max \\
\hline HC & $220.83 \pm 16.130$ & 198 & 245 \\
\hline AC & $112.33 \pm 7.659$ & 99 & 122 \\
\hline HT & $220.50 \pm 22.669$ & 191 & 251 \\
\hline AT & $112.17 \pm 15.250$ & 96 & 130 \\
\hline HC & After the exercise protocol & & \\
\hline AC & $234.00 \pm 12.884$ & 214 & 253 \\
\hline HT & $190.67 \pm 8.477$ & 176 & 200 \\
\hline AT & $251.17 \pm 13.045$ & 234 & 267 \\
\hline & $218.33 \pm 5.164$ & 210 & 224 \\
\hline
\end{tabular}

${ }^{\mathrm{a}} \mathrm{N}=6$.

${ }^{\mathrm{b}}$ Values are expressed as mean $\pm \mathrm{SD}$.

Figure 1. Comparison of Serum IFN- $\gamma$ and IL-17 Levels (mean \pm SD) Among Groups Before the Exercise Protocol

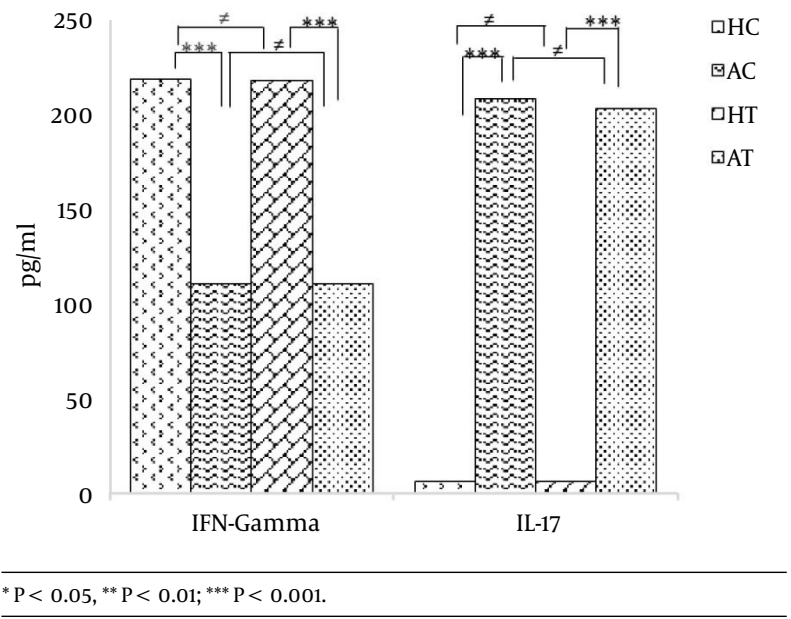

HT group compared with the HC group $(\mathrm{P}<0.05)$. Moreover, a significant increase in the serum IFN- $\gamma$ level of the AT group was observed compared with the AC group $(\mathrm{P}<$ 0.001). The obtained results are presented in Table 4 and Figure 2.

After 8 weeks of moderate exercise, the serum IL-17 level 
Table 3. Serum IL-17 Levels "Before" and "After" the Exercise Protocol in the Groups $(\mathrm{pg} / \mathrm{mL})^{\mathrm{a}}$

\begin{tabular}{lccc}
\hline & $\begin{array}{c}\text { Mean }^{\text {b }} \\
\text { Before the exercise protocol }\end{array}$ & Min & Max \\
\hline HC & $6.83 \pm 3.430$ & 4 & 13 \\
\hline AC & $210.67 \pm 18.228$ & 189 & 242 \\
\hline HT & $6.50 \pm 1.378$ & 5 & 8 \\
\hline AT & $205.83 \pm 22.507$ & 179 & 241 \\
\hline HC & After the exercise protocol & & \\
\hline AC & $38.17 \pm 7.68$ & 27 & 46 \\
\hline HT & $57.17 \pm 7.83$ & 48 & 69 \\
\hline AT & $22.67 \pm 4.46$ & 17 & 28 \\
\hline${ }^{a} \mathrm{~N}=6$. & $42.17 \pm 7.41$ & 34 & 50 \\
\hline${ }^{b}$ Values are expressed as mean \pm SD. & & \\
\hline
\end{tabular}

Table 4. The Results of Tukey's Test for the Groups Before and After Moderate Exercise With Regard to the Serum IFN- $\gamma$ Levels

\begin{tabular}{lcc}
\hline & $\begin{array}{c}\text { Mean Difference }^{\mathrm{a}} \\
\text { Groups Before Exercise }\end{array}$ & PValue \\
\hline HC AC & $108.500 \pm 9.711^{\mathrm{b}}$ & 0.000 \\
\hline HT AT & $108.333 \pm 9.711^{\mathrm{b}}$ & 0.000 \\
\hline HC HT & $0.333 \pm 9.711$ & 1.000 \\
\hline AC AT & $0.167 \pm 9.711$ & 1.000 \\
\hline & Groups After Exercise & \\
\hline HC AC & $43.333 \pm 6.670^{\mathrm{b}}$ & 0.000 \\
\hline HT AT & $32.833 \pm 6.670^{\mathrm{b}}$ & 0.000 \\
\hline HC HT & $-17.167 \pm 6.670^{\mathrm{b}}$ & 0.045 \\
\hline AC AT & $-27.667 \pm 6.670^{\mathrm{b}}$ & 0.000 \\
\hline
\end{tabular}

${ }^{\mathrm{a}}$ Values are expressed as mean $\pm \mathrm{SE}$.

${ }^{\mathrm{b}}$ The mean difference is significant at the 0.05 level.

in the AC group significantly increased compared with the HC group $(\mathrm{P}<0.001)$. Furthermore, a significant decrease in the IL-17 serum level in the HT group was observed compared with the AT group $(\mathrm{P}<0.001)$.

When comparing the HC and HT groups, the serum IL17 level of the HT group significantly decreased compared to the HC group $(\mathrm{P}<0.01)$. Furthermore, there was a significant decrease in serum IL-17 level of the AT group compared with the AC group $(\mathrm{P}<0.01)$. The obtained results are presented in Table 5 and Figure 2.
Figure 2. Comparison of Serum IFN- $\gamma$ and IL-17 Levels (Mean \pm SD) Among Groups at the End of Exercise

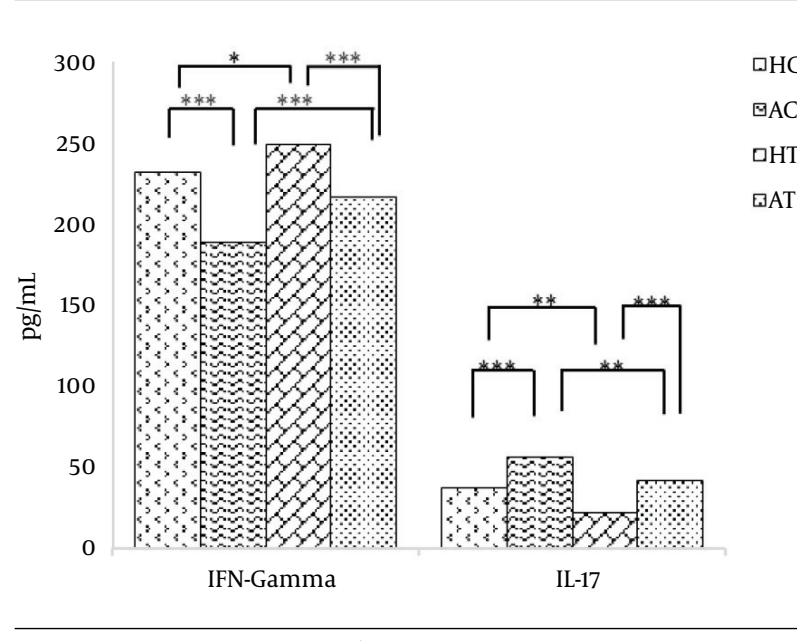

${ }^{*} \mathrm{P}<0.05,{ }^{* *} \mathrm{P}<0.01 ;{ }^{* * *} \mathrm{P}<0.001, \neq$ not significant.

Table 5. The Results of Tukey's Test for the Groups Before and After Moderate Exercise With Regard to the Serum IL-17 Levels

\begin{tabular}{|ccc}
\hline & $\begin{array}{c}\text { Mean Difference }^{\mathrm{a}} \\
\text { Groups Before Exercise }\end{array}$ & PValue \\
\hline HC AC & $-203.833 \pm 8.429^{\mathrm{b}}$ & 0.000 \\
\hline HT AT & $-199.333 \pm 8.429^{\mathrm{b}}$ & 0.000 \\
\hline HC HT & $0.333 \pm 8.429$ & 1.000 \\
\hline AC AT & $4.833 \pm 8.429$ & 0.939 \\
\hline HC AC & Groups After Exercise & \\
\hline HT AT & $-19.000 \pm 4.033^{\mathrm{b}}$ & 0.001 \\
\hline HC HT & $-19.500 \pm 4.033^{\mathrm{b}}$ & 0.001 \\
\hline AC AT & $15.500 \pm 4.033^{\mathrm{b}}$ & 0.005 \\
\hline
\end{tabular}

${ }^{\mathrm{a}}$ Values are expressed as mean $\pm \mathrm{SE}$.

${ }^{\mathrm{b}}$ The mean difference is significant at the 0.05 level.

\section{Discussion}

The findings of this study showed that during the early stage of morphine withdrawal syndrome before the beginning of the exercise protocol, the serum IFN- $\gamma$ levels declined in the AC and AT groups in comparison with the HC and HT groups. Furthermore, the serum IL-17 levels in the AC and AT groups increased compared to the HC and HT groups. On the other hand, in this phase there was no significant change in the weight of the animals in any of the four study groups. After 8 weeks of moderate exercise, changes in the serum IFN- $\gamma$ levels in the research groups showed that the highest serum levels of the cytokine be- 
longed to HT, HC, AT, and AC, respectively. Also, the lowest levels of serum IL-17 in the study groups belonged to HT, AT, $\mathrm{HC}$, and AC, respectively. In addition, regarding the weight changes, the HC, AC, HT, and AT groups gained the most to least weight, respectively.Experimental studies on withdrawal syndrome in rodents have reported an increase in sympathetic nervous system (SNS) activity, which, in turn, causes the release of noradrenaline (NE) from sympathetic nerve terminals and the adrenal medulla. West et al. reported a decrease in the level of serum IFN- $\gamma$ during morphine withdrawal in rats, a finding which was consistent with the hypothesis that indirectly increased sympathetic nervous system activity may cause suppression of the immune system (24). In the present study, a significant decrease was also observed in the serum IFN- $\gamma$ levels in the AC and AT groups prior to the start of the exercise protocol.

The decrease in cytokines may be due to the intense activity of the SNS, followed by increased secretion of the NE, which can be a factor for suppressing the immune system and reducing the production of IFN- $\gamma$. The hypothalamuspituitary-adrenal (HPA) axis may be one reason for the immune system suppression. During the withdrawal period in human samples, an increase in the secretion of anterior pituitary hormones, such as adrenocorticotropic (ACTH), and $\beta$-endorphin, and the adrenocortical glucocorticoid, such as cortisol, was also observed.

Experiments on animals also revealed high activity in the HPA axis. This increased activity observed during the withdrawal course quite possibly led to an increase in NE and suppression of the immune system. It can be explained that high activity of the SNS and HPA axis caused by drug withdrawal is involved in immune suppression (24).

In line with the findings of the present study, Kelschenbach et al. conducted a study on rats and concluded that the production of IFN- $\gamma$ was suppressed 24 hours after a morphine withdrawal period (25). Similarly, Rahim et al. have also noted similar results in their study (26). On the other hand, West et al. have reported the suppression of IFN- $\gamma 12$ hours after morphine withdrawal, while cytokine levels returned to normal only after 24 hours (24). The contradiction between the findings of West et al. and those in the present study may be due to the fact that they performed their study on Lewis Rats, while the animal samples used in the present research were Wistar Rats (24). On the other hand, Zhao et al. in a number of articles, noted that after moderate intensity exercise, the serum IFN- $\gamma$ level significantly increased (16). In another study, Shimizu et al. came to a similar conclusion (17). Many previous findings are in line with the findings of this study, but several studies have reached different conclusions confirming that the serum IFN- $\gamma$ level decreases after exercise. For example, Ranjbar et al. reported that after 30 minutes of
$50 \%$ vo2max intensive cycling and 2 hours after the exercise, the IFN- $\gamma$ level increased significantly, whereas there was no significant increase at higher values (27). After 8 weeks on a treadmill with a level of $55 \%-70 \% \mathrm{VO}_{2 \max }$ intensity, Zar et al. noted a decrease in the IFN- $\gamma$ level within 24 48 hours after the last session, but the registered decrease was not significant (28). In addition, White et al. reviewed a series of studies conducted on patients and reported a decrease in the IFN- $\gamma$ level after aerobic exercises (29). These differences could be due to the type, intensity, and duration of exercise protocols, some genetic and racial differences, and/or differences among samples, including both human and animal samples. Different physical, psychological, and digestive conditions of the samples could also be effective factors.

There are many reports confirming that moderate exercise drives the immune system toward Th1-type cytokine responses, such as IFN- $\gamma$, IL-2, and IL-12, while highintensity exercise increases the level of Th2 cytokines, such as IL-4, IL-6, and IL-10 (30). Hence, moderate-intensity exercise can explain the increase in the serum IFN- $\gamma$ level in the present study.

Strong Th1 responses such as IFN- $\gamma$ tend to inhibit Th17 development (31); however, immune suppression induced by withdrawal reduces the IFN- $\gamma$ level. This reduction leads to the possibility of fungal and bacterial activity in dendritic cells and triggers the increased production of cytokines, such as IL-1, IL-6, and IL-23. TGF- $\beta$, produced by many cells of the immune system in the presence of cytokines, such as IL-6 or IL-1, contributes to the development of pro-inflammatory Th17 cells. In collaboration with IL-6 and IL-1, TGF- $\beta$ induces the production of the ROR $\gamma$ t factor transcription. IL- 6 also activates the STAT3 transcription factor that, along with ROR $\gamma$ t, stimulates the differentiation of naive TCD4+ cells into the Th17 sub-category. Furthermore, IL-23 plays an important role in the proliferation and survival of Th17 cells (7). As a result of this cellular process, IL-17 originates from Th17 cells.

The increase in the IL-17 level during withdrawal syndrome could be caused by the significant increase in the risk of infection (32). The immune response of IL-17 involves the employment of neutrophils and protection against extracellular bacterial and fungal infections (21).

Since the production of cytokines is modulated by a range of physiological stimuli, such as sports and exercise (33), serum IL-17 level reduction might be considered a result of the impact of physical activities. The positive effect of moderate exercise on the immune system has been confirmed by many researchers. Lowder et al. found that moderate exercise reduces the production of Th2 and Th17 cytokines in both healthy and asthmatic rats (34). Golzari et al. and Sugama et al. have also stated that seemingly mod- 
erate exercise can decrease the serum IL-17 level $(18,20)$. However, in another study, Duzova et al. concluded that in the group with moderate-intensity exercise compared with the control group, the IL-17 level increased, although this increase was not significant (35).

$\mathrm{T} \gamma \delta$ cells that are considered IL-17-producing T-cells have been detected in adipose tissues (36). Increasing evidence suggests that IL-17 is a potent mediator of inflammatory responses in various tissues (37). Sumarac-Dumanovic et al. reported that both IL-17 and IL-23 levels were higher in the blood samples taken from obese people compared to those from lean participants (38). In a study on rats, Winer et al. also observed an increase in Th17 cell development and IL-17 production in rats that had become obese through a high-energy diet (39). There is a conflict between the cytokine production in Th1 and Th17 subsets (31). One reason for the decrease in the IL-17 level after moderate exercise can be the positive impact of this kind of exercise on increasing the serum IFN- $\gamma$ level and the inhibitory effect of cytokines on the development of Th17. Regarding the identification of IL-17-producing cells in adipose tissues such as $\mathrm{T} \gamma \delta$ cells, the reduction of the tissues after moderate exercise can decrease the production of this inflammatory cytokine.

A significant increase in the amount of IFN- $\gamma$ and a significant decrease in the serum IL-17 levels in the HT and AT groups compared to pre-workout levels indicate that the 8-week moderate exercise protocol used in this study could significantly affect the amount of these cytokines produced. However, regarding the IFN- $\gamma$ 's response to exercise, different results have been reported. The lack of consensus on the reported findings can be related to various factors including the variety of fitness tests, different levels of intensity and duration of activities, types of human or animal samples, and various methods and measurement tools.

It is known that the immune system demonstrates different responses to different exercises and narcotics. The results of the current research reveal that physical activity with moderate intensity, not only in healthy individuals, but also in those during the course of withdrawal, can play a significant role in increasing the IFN- $\gamma$ level as an inflammation-reducing cytokine. This type of exercise's effect of reducing the IL-17 level can also lead to a reduction of the negative effects of inflammation stimulated by this cytokine.

\section{Acknowledgments}

The authors would like to thank the members of the exercise physiology department for their suggestions and help in the research.

\section{Footnotes}

Authors' Contribution: Study concept and design: Ali Heidarianpour, acquisition of data: Ali Heidarianpour, and Majid Vahidian Rezazadeh; analysis and interpretation of data: Ali Heidarianpour, Majid Vahidian Rezazadeh, and drafting of the manuscript: Majid Vahidian Rezazadeh, critical revision of the manuscript for important intellectual content: Ali Heidarianpour, Statistical analysis: Ali Heidarianpour, and Majid Vahidian Rezazadeh; administrative, technical, and material support: Ali Heidarianpour, and Majid Vahidian Rezazadeh; study supervision: Ali Heidarianpour.

Financial Disclosure: This work was financially supported by a research grant from Bu-Ali Sina university, Hamadan, Iran. In addition, it should be noted that none of the authors had any conflict of interests during the undertaking of this research study and the preparation of this paper.

Funding/Support: This work was supported by research grant Bu-Ali Sina university, Hamadan, Iran.

\section{References}

1. Tompkins DA, Smith MT, Mintzer MZ, Campbell CM, Strain EC. A double blind, within subject comparison of spontaneous opioid withdrawal from buprenorphine versus morphine. J Pharmacol Exp Ther. 2014;348(2):217-26. doi: 10.1124/jpet.113.209478. [PubMed: 24227768].

2. Greeneltch KM, Kelly-Welch AE, Shi Y, Keegan AD. Chronic morphine treatment promotes specific Th2 cytokine production by murine $\mathrm{T}$ cells in vitro via a Fas/Fas ligand-dependent mechanism. J Immunol. 2005;175(8):4999-5005. [PubMed:16210602].

3. Arican O, Aral M, Sasmaz S, Ciragil P. Serum levels of TNF-alpha, IFN-gamma, IL-6, IL-8, IL-12, IL-17, and IL-18 in patients with active psoriasis and correlation with disease severity. Mediators Inflamm. 2005;2005(5):273-9. doi:10.1155/MI.2005.273. [PubMed:16258194].

4. Farrell PA, Joyner MJ, Caiozzo V, American College of Sports Medicine . ACSM's advanced exercise physiology. Wolters Kluwer Health/Lippincott Williams and Wilkins; 2012.

5. Febbraio MA, Pedersen BK. Muscle-derived interleukin-6: mechanisms for activation and possible biological roles. FASEB $J$. 2002;16(11):1335-47. doi:10.1096/fj.01-0876rev. [PubMed: 12205025].

6. Kohara H, Kitaura H, Fujimura Y, Yoshimatsu M, Morita Y, Eguchi T, et al. IFN-gamma directly inhibits TNF-alpha-induced osteoclastogenesis in vitro and in vivo and induces apoptosis mediated by Fas/Fas ligand interactions. Immunol Lett. 2011;137(1-2):53-61. doi: 10.1016/j.imlet.2011.02.017. [PubMed: 21338623].

7. Abbas AK, Lichtman AHH., Pillai S. Cellular and Molecular Immunology: with STUDENT CONSULT Online Access. Elsevier Health Sciences; 2014

8. Cua DJ, Tato CM. Innate IL-17-producing cells: the sentinels of the immune system. Nat Rev Immunol. 2010;10(7):479-89. doi: 10.1038/nri2800. [PubMed: 20559326].

9. Huckans M, Fuller BE, Olavarria H, Sasaki AW, Chang M, Flora KD, et al. Multi-analyte profile analysis of plasma immune proteins: altered expression of peripheral immune factors is associated with neuropsychiatric symptom severity in adults with and without chronic hepatitis C virus infection. Brain Behav. 2014;4(2):123-42. doi: 10.1002/brb3.200. [PubMed: 24683507]. 
10. Weaver CT, Hatton RD, Mangan PR, Harrington LE. IL-17 family cytokines and the expanding diversity of effector $\mathrm{T}$ cell lineages. Annu Rev Immunol. 2007;25:821-52. doi: 10.1146/annurev.immunol.25.022106.141557. [PubMed: 17201677].

11. Dennison L, Moss-Morris R, Chalder T. A review of psychological correlates of adjustment in patients with multiple sclerosis. Clin Psychol Rev. 2009;29(2):141-53. doi: 10.1016/j.cpr.2008.12.001. [PubMed: 19167801].

12. Calabrese LH, Nieman DC. Exercise, immunity, and infection. J Am Osteopath Assoc. 1996;96(3):166-76. [PubMed: 8932593].

13. Owen AL, Wong DP, Dunlop G, Groussard C, Kebsi W, Dellal A, et al. High Intensity Training and Salivary Immunoglobulin-a Responses in Professional Top-Level Soccer Players: Effect of Training Intensity. J Strength Cond Res. 2014. doi: 10.1519/JSC.0000000000000380. [PubMed: 24448005].

14. Steensberg A, Toft AD, Bruunsgaard H, Sandmand M, HalkjærKristensen J, Pedersen BK. Strenuous exercise decreases the percentage of type1T cells in the circulation.JAppl Physiol. 2001;91(4):1708-12. [PubMed: 11568154].

15. Nieman DC, Pedersen BK. Exercise and immune function. Recent developments. Sports Med. 1999;27(2):73-80. [PubMed: 10091272].

16. Zhao G, Zhou S, Davie A, Su Q. Effects of moderate and high intensity exercise on T1/T2 balance. Exerc Immunol Rev. 2012;18:98-114. [PubMed: 22876723].

17. Shimizu K, Kimura F, Akimoto T, Akama T, Tanabe K, Nishijima T, et al. Effect of moderate exercise training on T-helper cell subpopulations in elderly people. Exerc Immunol Rev. 2008;14:24-37. [PubMed: 19203082].

18. Sugama K, Suzuki K, Yoshitani K, Shiraishi K, Kometani T. IL-17, neutrophil activation and muscle damage following endurance exercise. Exerc Immunol Rev. 2012;18:116-27. [PubMed: 22876724].

19. Walsh NP, Gleeson M, Pyne DB, Nieman DC, Dhabhar FS, Shephard RJ, et al. Position statement. Part two: Maintaining immune health. Exerc Immunol Rev. 2011;17:64-103. [PubMed: 21446353].

20. Golzari Z, Shabkhiz F, Soudi S, Kordi MR, Hashemi SM. Combined exercise training reduces IFN-gamma and IL-17 levels in the plasma and the supernatant of peripheral blood mononuclear cells in women with multiple sclerosis. Int Immunopharmacol. 2010;10(11):1415-9. doi 10.1016/j.intimp.2010.08.008. [PubMed: 20797460].

21. Eid RE, Rao DA, Zhou J, Lo SF, Ranjbaran H, Gallo A, et al. Interleukin17 and interferon-gamma are produced concomitantly by human coronary artery-infiltrating $\mathrm{T}$ cells and act synergistically on vascular smooth muscle cells. Circulation. 2009;119(10):1424-32. doi: 10.1161/CIRCULATIONAHA.108.827618. [PubMed: 19255340].

22. Institute of Laboratory Animal Resources . Guide for the Care and Use of Laboratory Animals Washington, D.C: National Academy Press; 1996.

23. Calegari VC, Zoppi CC, Rezende LF, Silveira LR, Carneiro EM, Boschero AC. Endurance training activates AMP-activated protein kinase, in creases expression of uncoupling protein 2 and reduces insulin secretion from rat pancreatic islets. JEndocrinol. 2011;208(3):257-64. doi 10.1530/JOE-10-0450. [PubMed: 21212094].

24. West JP, Dykstra LA, Lysle DT. Immunomodulatory effects of morphine withdrawal in the rat are time dependent and reversible by clonidine. Psychopharmacology (Berl). 1999;146(3):320-7. [PubMed:
10541733]

25. Kelschenbach J, Barke RA, Roy S. Morphine withdrawal contributes to Th cell differentiation by biasing cells toward the Th2 lineage. J Immunol. 2005;175(4):2655-65. [PubMed: 16081842].

26. Rahim RT, Meissler JJ, Zhang L, Adler MW, Rogers TJ, Eisenstein TK. Withdrawal from morphine in mice suppresses splenic macrophage function, cytokine production, and costimulatory molecules. J Neuroimmunol. 2003;144(1-2):16-27. [PubMed:14597094].

27. Ranjbar R, Pirayesh Shirazi Nezhad M, Eslami R. Effect of Six Weeks of Endurance Training on Levels of Interferon Gamma in Tissue of Female Mice with Cancer. Switzerland Res ParkJ. 2013;102(10).

28. Zar A, Ebrahim K, Hovanloo F, Amani D. Effects of An 8-Week Endurance Training Course on Changes in Interferon Gamma and Leukocyte Subsets. I Isfahan Med School. 2012;30(185).

29. White LJ, Castellano V. Exercise and brain health-implications for multiple sclerosis: Part 1-neuronal growth factors. Sports Med. 2008;38(2):91-100. [PubMed: 18201113].

30. Malm C. Exercise immunology: the current state of man and mouse. Sports Med. 2004;34(9):555-66. [PubMed: 15294006].

31. Wilson NJ, Boniface K, Chan JR, McKenzie BS, Blumenschein WM, Mattson JD, et al. Development, cytokine profile and function of human interleukin 17-producing helper T cells. Nat Immunol. 2007;8(9):9507. doi: 10.1038/ni1497. [PubMed: 17676044].

32. Roy S, Ninkovic J, Banerjee S, Charboneau RG, Das S, Dutta R, et al. Opioid drug abuse and modulation of immune function: consequences in the susceptibility to opportunistic infections. $J$ Neuroimmune Pharmacol. 2011;6(4):442-65. doi: 10.1007/s11481-011-9292-5. [PubMed: 21789507].

33. Cruzat VF, Krause M, Newsholme P. Amino acid supplementation and impact on immune function in the context of exercise.J Int Soc Sports Nutr. 2014;11(1):61. doi:10.1186/s12970-014-0061-8. [PubMed: 25530736].

34. Lowder T, Dugger K, Estell K, Deshane J, Schwiebert L. Exercise increases regulatory $\mathrm{T}$ cell function and decreases Th2 and Th17 cytokine production in healthy and asthmatic mice. $J$ Immunol. 2010;184(1):97.15.

35. Duzova H, Karakoc Y, Emre MH, Dogan ZY, Kilinc E. Effects of Acute Moderate and Strenuous Exercise Bouts on IL-17 Production and Inflammatory Response in Trained Rats. J Sports Sci Med. 2009;8(2):21924. [PubMed: 24149529].

36. Ishigame H, Kakuta S, Nagai T, Kadoki M, Nambu A, Komiyama Y, et al. Differential roles of interleukin-17A and -17F in host defense against mucoepithelial bacterial infection and allergic responses. Immunity. 2009;30(1):108-19. doi: 10.1016/j.immuni.2008.11.009. [PubMed: 19144317].

37. Fujino S, Andoh A, Bamba S, Ogawa A, Hata K, Araki Y, et al. Increased expression of interleukin 17 in inflammatory bowel disease. Gut. 2003;52(1):65-70. [PubMed: 12477762].

38. Sumarac-Dumanovic M, Stevanovic D, Ljubic A, Jorga J, Simic M, Stamenkovic-Pejkovic D, et al. Increased activity of interleukin23/interleukin-17 proinflammatory axis in obese women. Int $J$ Obes (Lond). 2009;33(1):151-6. doi: 10.1038/ijo.2008.216. [PubMed: 18982006].

39. Winer S, Paltser G, Chan Y, Tsui H, Engleman E, Winer D, et al. Obesity predisposes to Th17 bias. Eur J Immunol. 2009;39(9):2629-35. doi: 10.1002/eji.200838893. [PubMed: 19662632]. 